
\title{
E Research Square \\ Serum IGFBP-2 in Systemic Sclerosis as a Protective Factor of Lung Dysfunction
}

\author{
Julien Guiot ( $\nabla$ J.Guiot@chu.ulg.ac.be )
}

CHU Liège https://orcid.org/0000-0001-7800-1730

\section{Makon-Sébastien Njock}

Centre hospitalier universitaire de Liege

\section{Béatrice André}

Centre hospitalier universitaire de Liege

\section{Fanny Gester}

Centre hospitalier universitaire de Liege

\section{Monique Henket}

Centre hospitalier universitaire de Liege

\section{Dominique de Seny}

Centre hospitalier universitaire de Liege

\section{Catherine Moermans}

Centre hospitalier universitaire de Liege

\section{Michel G. Malaise}

Centre hospitalier universitaire de Liege

\section{Renaud Louis}

Centre hospitalier universitaire de Liege

\section{Research article}

Keywords: IGF pathway, systemic sclerosis, interstitial lung disease, lung fibrosis, biomarkers.

Posted Date: July 27th, 2020

DOI: https://doi.org/10.21203/rs.3.rs-44894/v1

License: (c) (i) This work is licensed under a Creative Commons Attribution 4.0 International License. Read Full License 


\section{Abstract}

Background Systemic sclerosis (SSc) is a rare connective tissue disease associated with rapid evolving interstitial lung disease (SSc-ILD), driving its mortality. Specific biomarkers associated with the progression of this lung disease are highly needed. We aimed to identify specific biomarkers of SSc-ILD to predict the evolution of the disease.

Methods We compared prospectively serum levels of several biomarkers associated with lung fibrosis in SSc patients $(n=102)$ compared to healthy subjects $(H S)(n=39)$. We also performed a longitudinal study in a subgroup of 28 patients analyzing biomarkers variations and pulmonary function tests over a period of 2 years. Furthermore, we performed in vitro analysis to study the impact of Insulin like Growth Factor Binding Protein (IGFBP)-2 on fibrotic activity of human lung fibroblasts.

Results Serum levels of IGFBP-1, IGFBP-2, interleukin-8 and matrix metallopeptidase-9 were significantly increased in SSc patients compared to HS while IGF-1 and IGFBP-3 were reduced. The variation of IGFBP2 between baseline and 2-year follow-up was positively correlated with pulmonary function (assessed by carbon monoxide transfer coefficient (KCO)) at 2-year follow-up $(r=0.6, p<0.001)$. Receiver operating characteristic curve analysis enabled us to identify that baseline IGFBP- $2<105 \mathrm{ng} / \mathrm{ml}$ was associated with a better outcome (low risk to display $\mathrm{KCO}<70 \%$ predicted) at 2-year follow-up (area under the curve $=0.75$ at $75 \%$ sensibility and $68 \%$ specificity, $p<0.05$ ). In vitro functional study showed that IGFBP-2 significantly reduced fibroblast proliferation and pro-fibrotic activity.

Conclusions We showed for the first time that serum levels of IGFBP-2 might predict the evolution of SScILD. Baseline IGFBP-2 above $105 \mathrm{ng} / \mathrm{ml}$ might be a prognostic factor of alveolo-capillary dysfunction.

\section{Background}

Systemic sclerosis (SSc) is a complex systemic disease of unknown origin associated with a multiorganic affection involving a complex interplay of microvasculopathy, disturbances in fibroblastic function and abnormalities of the immune system [1,2]. One of the major complications of that pathology driving the mortality of the patients is the interstitial lung disease (ILD) [3,4] with an estimated incidence ranging from $40-75 \%[5,6]$. The main pathological pattern associates vascular inflammation leading to a progressive fibrosing process characterized by excessive collagen production. This collagen deposition is leading to tissue fibrosis of the skin and the internal organs reducing its functionality [7]. The main organ involved in the SSc is the skin. Besides the skin, kidneys and lungs are frequently attacked. In lungs, SSc is expressed as a chronic interstitial lung disease (SSc-ILD) having many common clinical and pathological characteristics with some other major ILDs, mainly idiopathic pulmonary fibrosis (IPF) [8-11].

As it is described in many other ILDs, SSc-ILD is associated with multiple clinical phenotypes. It can progress with a wide spectrum of course ranging from a rapid progressive lung disease as well as a slow evolving ILD but also a non-progressive ILD. Contrary to what is seen in IPF [12], treatment is mainly 
based on an aggressive immunosuppressive therapy specifically proposed in the progressive forms of SSc-ILD. One of the major problem clinicians have to deal with, as in other ILD, is to identify patients at increased risk of progression for early intervention [5,13-16]. In this context, biomarkers are highly needed in order to help clinicians for diagnosis, prognosis and the evaluation of the therapeutic response. The ideal biomarker would be a good predictors in SSc-ILD [14, 17]. Although antinuclear antibodies (ANA) were the first biomarkers available, those biomarkers do not allow for disease activity monitoring $[18,19]$.

The transforming growth factor beta (TGF- $\beta$ ) is known to be involved in the pathophysiology of many lung fibrotic diseases by stimulating the deposition of collagen and increasing lung remodeling $[20,21]$. TGF- $\beta$ is also widely known as an inducer of fibroblast activity. Besides TGF- $\beta$, previous studies identified that insulin-like growth factor-binding proteins (IGFBPs) were also clearly associated with IPF [22] and of interest as new potential biomarkers [23].

Insulin-like growth factors (IGFs) are peptides growth factors playing a crucial role in normal growth and development in many tissues as well as in maintaining cellular homeostasis by regulating several cellular processes (such as cell proliferation, differentiation, metabolism) [24]. IGFs are found in serum and other biofluids associated with IGFBPs. Through the sequestration of IGFs, IGFBPs regulate IGF stability, transport and tissue distribution, thus determining the bioavailability and biological activity of IGFs [25]. It has been shown that IGFBPs can inhibit or potentiate IGF activities in vitro depending on cell type and experimental conditions [26]. The main IGFBPs described in ILD context are IGFBP-1 and IGFBP-2. It has been shown that IGFBP-1 and -2 were able to improve tissue repair in inflammatory conditions by increasing fibroblast proliferation and migration [27]. In SSc context, IGF-1 and IGFBP-3 are involved in abnormal repair process $[28,29]$. Further, elevated levels of IGFBP-2 were found in broncho-alveolar lavage fluid of ILD patients [30], but also in serum and sputum of IPF patients [15, 31].

We focused our study on the quantification of several serum growth factors including IGFs and IGFBPs in order to identify a potential new biomarker for SSc and sought to determine whether these biomarkers might influence the evolution of the disease.

\section{Methods}

\section{Subject characteristics}

In this study, we prospectively recruited patients with SSc $(\mathrm{n}=102)$ from our ambulatory clinic at CHU Liege from 2010 to 2018 and compared them to healthy subjects (HS) $(n=39)$ (Fig. 1). The diagnosis of SSc was made according to the international recommendations of ACR/Eular [7]. SSc-ILD was defined by a combination of specific HRCT images of at least $10 \%$ of all parenchyma (reticulations, honey combing and/or ground glass opacities) with clinical signs (velcros or crackels) or symptoms (cough, shortness of breath) and alteration of pulmonary function tests. We excluded all other causes of interstitial lung disease (such asbestosis, idiopathic pulmonary fibrosis, idiopathic non specific interstitial pneumonia, 
hypersensitivity pneumonitis or toxic pneumonitis). All cases were validated after a multidisciplinary discussion in order to confirm the presence or absence of SSc-ILD. Then, we performed a longitudinal study, resampling blood 2 years after the first analysis $(n=28)$ (Fig. 1). HS were recruited by advertisement in our policlinic waiting room. They all denied any respiratory disease and had normal spirometric values with FEV1 $>80 \%$ predicted and FEV1/FVC ratio $>70 \%$. The protocol was approved by the ethics committee of $\mathrm{CHU}$ of Liège, and all subjects gave written consent be for their enrollment (Belgian number: B707201422832; ref : 2014/302).

\section{Pulmonary function tests}

All tests were performed according to the recommendations of the European Respiratory Society (ERS). The results were expressed in percent predicted. The total lung capacity (TLC) was measured by body plethysmography and expressed in percent predicted. The diffusion capacity of CO (DLCO) and the report DLCO/AV (alveolar volume) were measured by the single-breath carbon monoxide gas transfer method and expressed in percent predicted (SensorMedics2400He /CO Analyzer System, Bilthoven, Netherlands).

\section{Biomarkers measurements in serum}

Levels of Interleukin (IL)-8, tumor necrosis factor (TNF)-a, matrix metalloproteinase (MMP)-7, Chitinase-3like protein 1 (YKL-40). IGFBP-1 and IGFBP-3 were assessed by ELISA multiplex using Fluorokine-1. Multianalyte Profiling Kits (R\&D Systems, Minneapolis, MN, USA) according to the manufacturer's instructions. The detection limit for this assays were 3-3-200-230-170-705 pg/ml respectively. The concentration of the other proteins were measured separately by ELISA: TGF- $\beta$, MMP-9, IGF-1, IGFBP-2. (DuoSet kit, R\&D systems); The detection limits for these kits were 7-25-25-32 pg/ml respectively.

\section{Fibroblast isolation}

Primary control human lung fibroblast (HLF) were obtained from around $500 \mathrm{mg}$ specimen of healthy lung from surgery indicated for lung tumor resection in University Hospital from Liège, Belgium. The specimen were cut in part of 3 to $5 \mathrm{~mm}$ size and transferred in a gentle MACS ${ }^{\mathrm{TM}} \mathrm{C}$-tube (Myltenyi biotech ${ }^{\mathrm{TM}}$, Benelux) containing a mixture of HBSS with red phenol (Lonza ${ }^{\mathrm{TM}}$, Verviers, Belgium), inactivated FCS $5 \%$ $\left(\right.$ Invitroge $\left.{ }^{\mathrm{TM}}\right)$, collagenase A $1 \mathrm{mg} / \mathrm{ml}\left(\right.$ Roche $\left.^{\mathrm{TM}}\right)$ and Dnase I $0.05 \mathrm{mg} / \mathrm{ml}\left(\right.$ Roche $\left.^{\mathrm{Tm}}\right)$. The tissue was dissociated with a gentle MACS ${ }^{\mathrm{TM}}$ Dissociator (Myltenyi biotech, Benelux) according to manufacturer's recommendations and digested in the enzymatic mixture during one hour at $37^{\circ} \mathrm{C}$ under agitation. After a supplementary step of dissociation, the cell suspension was filtered on a $70 \mu \mathrm{m}$ cells strainer (Corning Falcon ${ }^{\circledR}$ ) and washed in $50 \mathrm{ml}$ PBS (Lonza $\left.{ }^{\mathrm{TM}}\right)+10 \mathrm{mM}$ EDTA. Then cells were plated in a $75 \mathrm{~cm}$ flask and cultured in DMEM (Gibco®) containing 2mMGlutamine (Gibco®), 10\% inactivated Foetal Calf Serum (FCS) (Invitrogen $\AA$ ), $0.1 \%$ fungizone (Gibco $\AA$ ) $100 \mathrm{U} / \mathrm{ml}$ penicillin and $100 \mathrm{mg} / \mathrm{ml}$ steptomycin (Gibco $\AA$ ) in a humidified incubator at $37^{\circ} \mathrm{Cand} 5 \% \mathrm{CO} 2$. The medium was changed twice a week and after 14 days, cells reached confluence. Cells were harvested by treatment with trypsin /EDTA (Lonza ${ }^{\mathrm{TM}}$ ). All experiment were performed with cell between passage 3 and 5

\section{Protein measurement}




\section{Cell culture}

60000 cells were plated into 12 well plate and cultured in $800 \mu$ DMEM supplemented with $2 \mathrm{mMGlutamine}, 0.1 \%$ fungizone (Gibco®) $100 \mathrm{U} / \mathrm{ml}$ penicillin and $100 \mathrm{mg} / \mathrm{ml}$ steptomycin (Gibco $\AA$ ) and $10 \%$ inactivated FCS. When cells reached $80 \%$ of confluence, the medium was removed and replaced by medium with $2 \%$ inactivated serum or without serum alone or in presence of TGF- $\beta 5 \mathrm{ng} / \mathrm{ml}$ (R\&D Systems Europe, Abingdon, UK). After $48 \mathrm{~h}$ while culture mediums were recovered and conserved at $-20^{\circ} \mathrm{C}$ for protein measurement, cells were used after trypsinisation for FACS analysis and an immunocytochemistry to alpha-Smooth Muscle Actin (a-SMA) were performed on adherent cells

\section{IGFBP-2 and Pro-col-1 ELISA}

IGFBP-2 and Pro-col-1 were measured in culture supernatant by commercial Kits ELISA (DUOSET kit from R\&D Systems Europe, Abingdon, UK) according to instructions provided by the manufacturer. The detection limits was 32 and $62 \mathrm{pg} / \mathrm{ml}$ respectively. The culture medium was diluted $5 x$ for IGFBP-2 and 1000x for Pro-Col-1 measurement.

\section{a-SMA immunocytochemistry}

After permeabilization with cold methanol and blocking 30 minute with SAB $2 \%$ in DPBS, cells were washed and stained with Human a-SMA mouse monoclonal antibody (DAKO M0851) diluted 1/1000. The detection was performed with Envision + HRP system anti mouse (DAKO K4000) and the DAB + substrate chromogen (DAKO K3468) according to instructions provided by the manufacturer. Cells were counterstained 5 secondes with Hemacolor ${ }^{\circledR}$ solution fixation 3 (Merck)

\section{a-SMA FACS analysis}

Cells from each well were washed with DPBS fixed in 4\% paraformaldehyde for 10 min washed twice with FACS buffer: DPBS, Serum Albumin Bovine 0.2\%. Saponin 0.5\%, Sodium Azide 0.1\% (Sigma-Aldrich, Belgium). And were stained with a human a-SMA-APC-conjugated Antibody (R\&D systems) or with the corresponding isotype control: Mouse IgG2A APC-conjugated Antibody (R\&D systems). After 20 min. of incubation at $4{ }^{\circ} \mathrm{C}$, cells were washed with DPBS and analysed on a FACS Aria II (BD) flow cytometer .

\section{Viability and Proliferation measurement}

8000 cells were plated into 96 well plate and cultured in $200 \mu$ DMEM supplemented with $2 \mathrm{mM}$ Glutamine, antibiotics and $10 \%$ inactivated FCS. When cells reached $80 \%$ of confluence, cells were deprived of serum during $24 \mathrm{~h}$ then cultured in medium free serum. After $48 \mathrm{~h}, \mathrm{HLF}$ viability and proliferation were evaluated. BrdU (5-bromo-2-deoxyuridine) cell Proliferation Assay Kit were performed according to instructions provided by the manufacturer Cell signaling Technology ${ }^{\circledR}$,Europe : At the end of the culture, $20 \mu \mathrm{lBrDU}$ were added into wells. After $4 \mathrm{~h}$ of incubation $\left(37^{\circ} \mathrm{C}-5 \% \mathrm{CO} 2\right)$ cells were fixed and labeled with an BrdU antibody. The revelations were performed with the system Biotin/HRP. The BrdU incorporation was detected by measuring the absorbance at $450 \mathrm{~nm}$

\section{Statistical analysis}


Demographic and functional data were expressed as mean \pm standard deviation (SD). The biomarkers levels were expressed as median (IQR). Comparisons between groups were performed by Mann-Witney and unpaired " $\mathrm{t}$ " test according to the distribution of the variable. Correlations between variables were performed using Spearman's rank correlation test. A $p<0.05$ was considered as significant. Statistical analysis and graph were performed with Prism Graph Pad software® v6. San Diego.

\section{Results}

\section{Study population, patient characteristics, and clinical data}

We prospectively recruited patients with SSc $(n=102)$ from our ambulatory care policlinic at CHU Liege and compared them to healthy subjects (HS) $(n=39)$ (Fig. 1). Demographic, functional and treatment characteristics of the subjects are given in Table 1. The average age of patients compared to healthy subjects (HS) was similar. FEV1 and FVC were moderately lowered in the SSc group $(p<0.01$ and $p<$ 0.001 , respectively). SSc patients displayed a reduced DLCO (66 $\pm 20 \%$ predicted). Of note $38 \%$ of our SSc cohort were suffering from SSc-ILD based on chest CT. The blood cell count analysis showed that patient with SSc exhibited higher levels of neutrophils $(p<0.001)$ and reduced levels of lymphocytes $(p<0.001)$ compared to HS. By contrast, circulating monocytes, eosinophils and basophils were similar in the two groups (Table 1). Of note $30 \%$ of patients were receiving maintenance treatment with immunosuppressive drugs and $27 \%$ were receiving oral corticosteroids. 
Table 1

Demographic and clinical characteristics of HS and SSc patients.

\begin{tabular}{|c|c|c|}
\hline & $\begin{array}{l}\text { HS } \\
(n=39)\end{array}$ & $\begin{array}{l}\text { SSc } \\
(n=102)\end{array}$ \\
\hline Age, yrs & $59 \pm 10$ & $58 \pm 12$ \\
\hline Gender (M/F) & $13 / 26$ & $27 / 75$ \\
\hline $\mathrm{BMI}, \mathrm{Kg} / \mathrm{m}^{2}$ & $26 \pm 4$ & $25 \pm 5$ \\
\hline Smokers (NS/FS/S) & $17 / 16 / 6$ & $54 / 28 / 20$ \\
\hline Paq-year & $12 \pm 18$ & $9 \pm 13$ \\
\hline leuco x10e3/ $\mu$ l & $7 \pm 1.5$ & $7.5 \pm 2.2$ \\
\hline Neutrophil \% & $55 \pm 7$ & $65 \pm 9 * \star \star$ \\
\hline Cell $/ \mathrm{mm}^{3}$ & $3842 \pm 1156$ & $4999 \pm 1985^{\star \star}$ \\
\hline Lymphocyte \% & $35 \pm 7$ & $24 \pm 9 * \star \star$ \\
\hline Cell $/ \mathrm{mm}^{3}$ & $2389 \pm 570$ & $1739 \pm 684^{\star \star \star}$ \\
\hline Monocyte \% & $7.7 \pm 2.3$ & $7.9 \pm 2.4$ \\
\hline Cell $/ \mathrm{mm}^{3}$ & $531 \pm 168$ & $586 \pm 221$ \\
\hline Eosinophil \% & $2.3 \pm 1.8$ & $2.1 \pm 1.3$ \\
\hline Cell $/ \mathrm{mm}^{3}$ & $155 \pm 109$ & $151 \pm 96$ \\
\hline Basophil \% & $0.5 \pm 0.3$ & $0.5 \pm 0.3$ \\
\hline Cell $/ \mathrm{mm}^{3}$ & $36 \pm 15$ & $37 \pm 21$ \\
\hline FEV1 post-BD, \%pred. & $106 \pm 18$ & $94 \pm 23^{\star *}$ \\
\hline FVC post-BD, \%pred. & $112 \pm 18$ & $98 \pm 22^{\star \star \star}$ \\
\hline TLC, \%pred. & - & $95 \pm 18$ \\
\hline DLCO, \%pred. & - & $66 \pm 20$ \\
\hline KCO, \%pred. & - & $77 \pm 18$ \\
\hline Immunosupressor (yes/no) & $0 / 39$ & $31 / 71$ \\
\hline OCS (yes/no) & $0 / 39$ & $28 / 74$ \\
\hline ILD (yes/no) & - & $39 / 63$ \\
\hline Disease duration (y) & - & $6,9 \pm 7,9$ \\
\hline Rodnan skin score & - & $3,9 \pm 5,8$ \\
\hline
\end{tabular}




\begin{tabular}{|lll|}
\hline & $\begin{array}{l}\text { HS } \\
(\mathbf{n}=\mathbf{3 9})\end{array}$ & $\begin{array}{l}\text { SSc } \\
(\mathbf{n}=102)\end{array}$ \\
\hline ACR/Eular score & - & $11 \pm 5,5$ \\
\hline Limited SSc/lcSSc/dSSc/ SS & - & $31 / 51 / 10 / 3$ \\
\hline Musculoskeletal involvement (\%) & - & 11 \\
\hline Renal crisis (\%) & - & 3 \\
\hline Cardiac involvement (\%) & - & 3 \\
\hline
\end{tabular}

Data are expressed as mean \pm SD. ${ }^{*} p<0.05 * * p<0.001 * * * p<0.0001$ compared to HS.

Abbreviations: dSSc = diffuse cutaneous SSc; DLCO = Diffusion lung capacity for C0; FEV1 = Forced expired volume in one second; FS = Former smoker; FVC = Forced Vital Capacity; HS = healthy subjects; ILD = Interstitial lung disease; IT = Immunosuppressive therapy (Mycophenolate Mofetil, methotrexate, cyclophosphamide); $\mathrm{KCO}=$ The carbon monoxide transfer coefficient; IcSSc = limited cutaneous SSc; NS = Non smoker; OCS = Oral corticosteroid; $\mathrm{S}=$ smoker; $\mathrm{SS}$ = Sine scleroderma; SSc = Systemic sclerosis; TLC = Total lung capacity.

\section{Serum biomarkers at baseline}

First, we compared the levels of different serum biomarkers associated with lung fibrosis (IGF-1, IGFBP-1, IGFBP-2, IGFBP-3, TGF- $\beta$, IL-8, TNF- $\alpha$, YKL-40, MMP-7, MMP-9 and CRP) between HS and SSc groups (concentrations are listed in Table 2). There is a significant increase in IGFBP-1 (8 to $12.9 \mathrm{ng} / \mathrm{ml}, p<0.05$ ), IGFBP-2 (83 to $117 \mathrm{ng} / \mathrm{ml}, \mathrm{p}<0.001$ ), IL-8 (3.6 to $9.3 \mathrm{pg} / \mathrm{ml}, \mathrm{p}<0.001)$, MMP-9 (412 to $967 \mathrm{ng} / \mathrm{ml}, \mathrm{p}<$ 0.001 ) and CRP ( 0.7 to $2.1 \mathrm{mg} / \mathrm{l}, \mathrm{p}<0.001$ ) levels in SSc patients compared to HS (Fig. 2b, c, e, f) (Table 2). Of note, IGF-1 and IGFBP-3 were significantly reduced SSc patients compared to HS (13 to $8.9 \mathrm{ng} / \mathrm{ml}, \mathrm{p}<0.05$; and 806 to $694 \mathrm{ng} / \mathrm{ml}, \mathrm{p}<0.05$, respectively) (Fig. 2a, d). We did not find any significant correlations between biomarkers and therapies at baseline (immunosuppressive agent or systemic corticosteroids). 
Table 2

Concentrations of serum biomarkers in HS and SSc patients.

\begin{tabular}{|c|c|c|}
\hline & $\begin{array}{l}\text { HS } \\
(n=39)\end{array}$ & $\begin{array}{l}\text { SSc } \\
(n=102)\end{array}$ \\
\hline IGF-1 (ng/ml) & $13(8-17)$ & $8.9(5.1-15.3)^{\star}$ \\
\hline IGFBP-1 (ng/ml) & $8(3-16)$ & $12.9(5.4-24)^{*}$ \\
\hline IGFBP-2 (ng/ml) & $83(51-109)$ & $117(73.8-177.6)^{\star \star \star}$ \\
\hline IGFBP-3 (ng/ml) & $806(675-926)$ & $694(571-861)^{\star}$ \\
\hline ratio IGF-1/IGFBP-1 & $5(3-15)$ & $2.8(0.9-10.2)^{*}$ \\
\hline ratio IGF-1/IGFBP-2 & $0.7(0.4-1.4)$ & $0.3(0.2-0.9)^{\star \star \star}$ \\
\hline ratio IGF-1/IGFBP-3 & $0.1(0-0.1)$ & $0.1(0-0.1)$ \\
\hline TGF- $\beta$ (ng/ml) & $26(24-31)$ & $29(24-35)$ \\
\hline IL-8 (pg/ml) & $3.6(1.5-7)$ & $9.3(3.8-17.4)^{\star \star \star}$ \\
\hline TNF-a (pg/ml) & ND & ND \\
\hline YKL-40 (ng/ml) & $33(24-49)$ & $42(22-63)$ \\
\hline MMP-7 (ng/ml) & $1.7(1.4-2)$ & $2(1.3-3.5)$ \\
\hline MMP-9 (ng/ml) & $412(221-818)$ & $967(444-1422)^{\star \star \star}$ \\
\hline CRP (mg/l) & $0.7(0.3-1.2)$ & $2.1(0.8-5.4)^{\star \star \star}$ \\
\hline \multicolumn{3}{|c|}{ 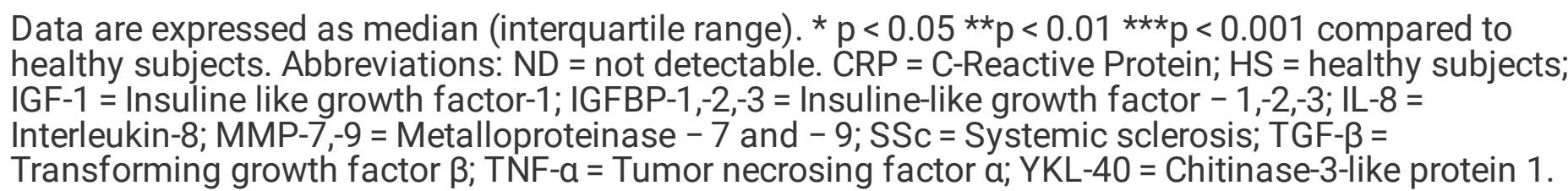 } \\
\hline
\end{tabular}

\section{Correlation between serum biomarkers and pulmonary function tests at baseline}

We performed correlation analysis to assess whether biomarkers were associated with pulmonary function tests at baseline. The correlation matrix is shown in Table 3. IGFBP-2 was negatively correlated with alveolo-capillar function assessed by carbon monoxide transfer coefficient $(K C O)(r=-0.29, p<0.01)$ (Fig. 3). In addition, YKL-40 was also negatively correlated with Forced Vital Capacity (FVC) as well as the Diffusion Lung capacity for CO (DLCO) $(r=-0.31, p<0.01$ and $r=-0.24, p<0.05$ respectively) (Table 3 ). 
Table 3

Spearman correlation evaluating serum biomarkers at baseline in comparison with pulmonary function tests.

\begin{tabular}{|c|c|c|c|c|c|}
\hline & FEV1\%pred. & FVC \%pred. & TLC, \%pred. & DLCO, \%pred. & KCO, \%pred. \\
\hline IGF-1 & -0.08 & -0.15 & $-0.23^{*}$ & -0.09 & 0.02 \\
\hline IGFBP-1 & 0.05 & 0.1 & $0.28 * \star$ & 0.05 & -0.2 \\
\hline IGFBP-2 & -0.13 & -0.12 & 0.16 & -0.16 & $-0.29 * \star$ \\
\hline IGFBP-3 & 0.08 & 0.06 & -0.01 & 0.07 & 0.12 \\
\hline TGF- $\beta$ & 0.04 & -0.03 & -0.02 & 0.15 & 0.03 \\
\hline IL-8 & -0.12 & -0.06 & -0.03 & -0.12 & -0.17 \\
\hline TNF-a & -0.12 & -0.07 & 0.14 & -0.08 & -0.15 \\
\hline YKL-40 & $-0.3^{\star \star}$ & $-0.31^{\star \star}$ & -0.14 & $-0.24^{\star}$ & -0.12 \\
\hline MMP-7 & -0.16 & -0.18 & $-0.2^{\star}$ & -0.16 & -0.05 \\
\hline MMP9 & -0.11 & -0.14 & -0.18 & -0.04 & 0.07 \\
\hline CRP & $-0.31 * \star$ & $-0.32 * \star$ & $-0.26^{\star}$ & -0.13 & 0.15 \\
\hline
\end{tabular}

Numbers represent the correlation coefficient $(r), p<0.05, * * p<0.01$.

Abbreviations: $\mathrm{CRP}=\mathrm{C}$-Reactive Protein; $\mathrm{DLCO}=$ Diffusion lung capacity for CO; FEV1 $=$ Forced expired volume in one second; FVC = Forced Vital Capacity; IGF-1 = Insuline like growth factor-1; IGFBP-1,-2,-3 = Insuline-like growth factor $-1,-2,-3$; IL-8 = Interleukin-8; KCO = The carbon monoxide transfer coefficient; MMP-7,-9 = Metalloproteinase -7 and $-9 ;$ TGF- $\beta=$ Transforming growth factor $\beta ;$ TLC = Total lung capacity; TNF- $\alpha=$ Tumor necrosing factor $\alpha$; YKL-40 = Chitinase-3-like protein 1 .

\section{Longitudinal analysis on serum biomarker variations and pulmonary function tests}

To assess whether the variation over the time of the levels of serum biomarkers was associated with pulmonary function declines, we performed a longitudinal study in a subgroup of 28 patients analyzing biomarkers variations and pulmonary function tests over a period of 2 years (Fig. 1). Demographic and biological characteristics of SSc patients at baseline and after 2 years are given in Table 4. The 2-year longitudinal analysis of pulmonary function revealed that only KCO was significantly reduced (Baseline: $81( \pm 14) \%$ and 2-years $73( \pm 12) \%, p<0.001)$ (Fig. 4a). There was no significant variation of the levels of serum biomarkers between baseline and 2-year follow-up (supplementary Table S1). Next, we performed analysis to determine if pulmonary function decline was associated to the variation of serum biomarkers (Table 5). Interestingly, we found a positive correlation between the variation of IGFBP-2 and KCO at 2year follow-up $(r=0.6, p<0.001)$ (Fig. 4b). ROC curve analysis enabled us to identify that baseline IGFBP- 
$2<105 \mathrm{ng} / \mathrm{ml}$ was associated with a better outcome assessed by KCO at 2 years follow-up in the overall SSc cohort (AUC 0.75 at $75 \%$ sensibility and $68 \%$ specificity) (Fig. 4c). Of note, we did not find any correlations between biomarkers evolution and immunosuppressive therapies. These results suggest a protective effect of IGFBP-2 on the progression of SSc disease. 
Table 4

Demographic and biological characteristics of SSc patients at baseline and 2-year follow-up.

\begin{tabular}{|c|c|c|}
\hline & $\begin{array}{l}\text { Baseline } \\
(n=28)\end{array}$ & $\begin{array}{l}2 \text { years follow-up } \\
(n=28)\end{array}$ \\
\hline Age, yrs & $57 \pm 12$ & $59 \pm 12$ \\
\hline Gender (M/F) & $22 / 6$ & $22 / 6$ \\
\hline $\mathrm{BMI}, \mathrm{Kg} / \mathrm{m}^{2}$ & $24 \pm 4$ & $24 \pm 4$ \\
\hline Smokers (NS/ES/S) & $14 / 10 / 5$ & $14 / 10 / 5$ \\
\hline Paq-year & $0(0-26)$ & $1(0-26)$ \\
\hline leuco x10e3/ $\mu$ l & $7 \pm 1.7$ & $7.8 \pm 2.8$ \\
\hline Neutrophil \% & $66 \pm 10$ & $64 \pm 12$ \\
\hline Cell $/ \mathrm{mm}^{3}$ & $4676 \pm 1696$ & $5257 \pm 2885$ \\
\hline Lymphocyte \% & $23 \pm 9$ & $24 \pm 10$ \\
\hline Cell $/ \mathrm{mm}^{3}$ & $1542 \pm 674$ & $1694 \pm 624$ \\
\hline Monocyte \% & $8 \pm 2.3$ & $8.1 \pm 2.7$ \\
\hline Cell $/ \mathrm{mm}^{3}$ & $555 \pm 199$ & $595 \pm 269$ \\
\hline Eosinophil \% & $2.6 \pm 1.3$ & $2.6 \pm 1.6$ \\
\hline Cell $/ \mathrm{mm}^{3}$ & $172 \pm 92$ & $185 \pm 126$ \\
\hline Basophil \% & $0.5 \pm 0.3$ & $0.5 \pm 0.3$ \\
\hline Cell $/ \mathrm{mm}^{3}$ & $35 \pm 16$ & $40 \pm 22$ \\
\hline FEV1 post-BD, \%pred. & $100 \pm 20$ & $98 \pm 19$ \\
\hline FVC post-BD, \%pred. & $103 \pm 20$ & $101 \pm 18$ \\
\hline TLC \%pred. & $95 \pm 16$ & $94 \pm 13$ \\
\hline DLCO \%pred. & $66 \pm 17$ & $65 \pm 13$ \\
\hline KCO \%pred. & $81 \pm 14$ & $73 \pm 12^{\star \star \star}$ \\
\hline ILD yes/no & $8 / 20$ & $11 / 17$ \\
\hline
\end{tabular}

Data are expressed as mean (SD). ${ }^{*} p<0.05 * * p<0.01 * * * p<0.001$ compared to Baseline.

Abbreviations: DLCO = Diffusion lung capacity for CO; FEV1 = Forced expired volume in one second; FS = Former smoker; FVC = Forced Vital Capacity; ILD = Interstitial lung disease; IT = Immunosuppressive therapy (Mycophenolate Mofetil, methotrexate, cyclophosphamide); $\mathrm{KCO}=$ The carbon monoxide transfer coefficient; NS = Non smoker; OCS = Oral corticosteroid; $\mathrm{S}$ = smoker; SSc: Systemic sclerosis; TLC = Total lung capacity. 


\begin{tabular}{|c|c|c|}
\hline & $\begin{array}{l}\text { Baseline } \\
(n=28)\end{array}$ & $\begin{array}{l}2 \text { years follow-up } \\
(n=28)\end{array}$ \\
\hline IT yes/no & $10 / 18$ & $10 / 18$ \\
\hline OCS yes/no & $5 / 23$ & $5 / 23$ \\
\hline \multicolumn{3}{|c|}{ Data are expressed as mean (SD). ${ }^{*} p<0.05^{\star *} p<0.01 * \star * p<0.001$ compared to Baseline. } \\
\hline \multicolumn{3}{|c|}{$\begin{array}{l}\text { Abbreviations: DLCO = Diffusion lung capacity for CO; FEV1 = Forced expired volume in one second; } \\
\text { FS = Former smoker; FVC = Forced Vital Capacity; ILD = Interstitial lung disease; IT = } \\
\text { Immunosuppressive therapy (Mycophenolate Mofetil, methotrexate, cyclophosphamide); KCO = The } \\
\text { carbon monoxide transfer coefficient; NS = Non smoker; OCS = Oral corticosteroid; S = smoker; SSC: } \\
\text { Systemic sclerosis; TLC = Total lung capacity. }\end{array}$} \\
\hline
\end{tabular}

\section{Table 5}

Spearman correlation evaluating pulmonary function tests at 2 years follow-up in comparison with biomarker variation $(\Delta)$ between baseline and 2-year follow-up.

\begin{tabular}{|c|c|c|c|c|c|}
\hline & FEV1\%pred. & FVC \%pred. & TLC \%pred. & DLCO \%pred. & KCO \%pred \\
\hline$\Delta$ IGF-1 & 0.02 & 0.00 & 0.11 & 0.34 & 0.26 \\
\hline$\Delta$ IGFBP-1 & -0.09 & -0.12 & -0.03 & -0.08 & 0.03 \\
\hline$\Delta$ IGFBP-2 & -0.02 & -0.08 & -0.28 & 0.29 & $0.60 * \star \star$ \\
\hline$\Delta$ IGFBP-3 & 0.16 & 0.09 & 0.20 & $0.42 *$ & 0.11 \\
\hline$\Delta$ TGF- $\beta$ & 0.03 & 0.14 & 0.09 & 0.33 & 0.31 \\
\hline$\Delta \mathrm{IL}-8$ & -0.01 & -0.10 & -0.29 & -0.08 & 0.09 \\
\hline$\Delta$ YKL40 & 0.07 & -0.04 & -0.07 & -0.21 & -0.02 \\
\hline$\Delta \mathrm{MMP7}$ & 0.05 & -0.12 & -0.25 & -0.08 & 0.12 \\
\hline$\Delta \mathrm{MMP9}$ & 0.03 & 0.00 & 0.14 & -0.09 & -0.22 \\
\hline \multicolumn{6}{|c|}{ Numbers represent the correlation coefficient $(r),{ }^{\star} p<0.05,{ }^{* \star} p<0.01,{ }^{\star * \star} p<0.001$. } \\
\hline \multicolumn{6}{|c|}{$\begin{array}{l}\text { Abbreviations: DLCO = Diffusion lung capacity for CO; FEV1 = Forced expired volume in one second; } \\
\text { FVC = Forced Vital Capacity; IGF-1 = Insuline like growth factor- } 1 \text {; IGFBP-1,-2,-3= Insuline-like growth } \\
\text { factor - 1,-2,-3; IL-8 = Interleukin-8; KCO = The carbon monoxide transfer coefficient; MMP-7,-9 = } \\
\text { Metalloproteinase - } 7 \text { and }-9 ; \text { SSC = Systemic sclerosis; TGF- } \beta=\text { Transforming growth factor } \beta ; \text { TLC = } \\
\text { Total lung capacity; YKL-40 = Chitinase-3-like protein } 1 \text {. }\end{array}$} \\
\hline
\end{tabular}

\section{Impact of IGFBP-2 on fibrotic and proliferative processes}

In order to elucidate the impact of IGFBP-2 on the progression of SSc disease, we investigated its effect on SSc-related processes in vitro.

\section{IGFBP-2 secretion is reduced in pro-fibrotic context}


First, we investigated the secretion of IGFBP-2 by human lung fibroblasts (HLFs) at basal state (FCS free) and in pro-proliferative condition (FCS, $2 \%$ ). Both quiescent and proliferating HLFs actively secrete IGFBP2. Proliferating HLFs produce more IGFBP-2 $(4062 \pm 141 \mathrm{pg} / \mathrm{ml})$ than quiescent HLFs $(958 \pm 445 \mathrm{pg} / \mathrm{ml})$ (Fig. 5a). Then, we investigated the impact of pro-fibrotic factor TGF- $\beta$ on the secretion of IGFBP-2. Under TGF- $\beta$ stimulation, we observed a reduction of IGFBP-2 secretion in proliferating HLFs (2945 \pm $1074 \mathrm{pg} / \mathrm{ml})(p<0.05)$. TGF- $\beta$ stimulation has no effect on the secretion of IGFBP-2 on quiescent HLFs.

\section{IGFBP-2 reduces the proliferation of HLF fibroblasts}

Then, we studied the effect of IGFBP-2 on HLF proliferation by BrdU assay. In presence of IGFBP-2 $(100 \mathrm{ng} / \mathrm{ml})$, we observed a significant decrease in BrdU incorporation at $48 \mathrm{~h}$, which reveals a reduction of HLF proliferation $(p<0.05)$ (Fig. $5 b)$. As expected, the positive control $($ TGF- $\beta$ ) increases the proliferation of HLF fibroblasts.

\subsubsection{IGFBP-2 reduces the fibrotic activity of HLF fibroblasts}

The impact of IGFBP-2 on fibrotic activity of HLF fibroblasts was first assessed by measuring the level of a-SMA via immunocytochemistry (Fig. 5c) and FACS analysis (Fig. 5d), then completed by the quantification of pro-collagen I secretion (Fig. 5e). In presence of IGFBP-2, we observed by FACS a decrease of a-SMA levels in HLF fibroblasts (Fig. 5d). Furthermore, the secretion of pro-collagen I was also significantly reduced by $35 \%$ in presence of IGFBP-2 $(p<0.05)$ (Fig. $5 e)$. The immunocytochemistry analysis did not show any difference without or with IGFBP-2.

Taken together, these results highlight the anti-proliferative and anti-fibrotic properties of IGFBP-2.

\section{Discussion}

Our study highlights the involvement of the IGF/IGFBP pathway in SSc disease. SSc patients featured a marked increase in serum levels of IGFBP-1, IGFBP-2, IL-8 and MMP-9 whereas IGF-1 and IGFBP-3 were significantly reduced compared to HS. Of interest, IGFBP-2 was correlated to KCO at baseline. Two-year longitudinal analysis determined that IGFBP-2 variation was positively correlated with the KCO measurement. Of great interest, initial levels of IGFBP-2 at baseline under $105 \mathrm{ng} / \mathrm{ml}$ were associated with better $\mathrm{KCO}$ at 2-years, suggesting the protective effect of IGFBP-2 on lung disease. In vitro functional analysis confirmed the anti-fibrotic property of IGFBP-2. Indeed, we identified that IGFBP-2 was able to reduce fibroblastic proliferation as well as global fibrogenic process (a-SMA and pro-col-I).

In previous studies, we have identified that IGFBP-2 was positively associated with lung fibrosis in serum and induced sputum of IPF patients [22, 31]. Moreover, IGFBP-2 was reduced in IPF patients receiving anti-fibrotic therapy, although serum levels remained higher in IPF patients than in HS [22]. Other studies focusing on IGFBP-2 in lung fibrosis identified a significant increase in broncho-alveolar lavage fluid and in lung tissue of interstitial lung diseases without focusing on systemic sclerosis [30]. In this study, we 
showed that patients suffering from SSc exhibited higher levels than HS but to a lesser extend than patients suffering from IPF as previously shown in one of our study [22,31]. Of interest, we identified that level variation of IGFBP-2 was associated with the severity of lung evolution. Indeed, baseline serum level of IGFBP-2 under $105 \mathrm{ng} / \mathrm{ml}$ allows identifying patients with a good prognosis based on a better KCO at 2-year follow-up (above 70\% pred) (DLCO/VA). This interesting observation suggests the potential prognostic value of baseline IGFBP-2 to identify SSc patients with risk of rapid evolution. Integrating new biomarkers in the follow up of SSc-ILD is challenging taking into account the variability of other clinical markers like symptoms, CRP, DLCO or FVC. Moreover, it is suitable to avoid repeated chest imaging in the follow-up of the patients to limit as much as possible irradiation. The use of serum biomarker IGFBP-2 could be a good candidate to predict the progression of SSC-ILD and need to be explored.

IGFBP-2 was able to reduce significantly fibroblast proliferation and the expression of two pro-fibrotic factors, pro-col-I and a-SMA, revealing its capacity to fight against fibrosis. The upregulation of antifibrotic IGFBP-2 in SSc patients is probably a process to fight against fibrogenesis and to slow the progression of the disease. Similarly, other studies focusing on human dermal fibroblasts identified that IGFBP-2 inhibited IGF-induced fibroblastic proliferation [25, 32, 33]. Of note, the inhibitory effect of IGFBP2 was reduced when it was cleaved by metalloproteases like MMP-9 [34], which was also increased in our present study in SSc group. Accordingly, increased MMP-9 levels due to neutrophilic activation could reduce simultaneously the regulatory effect of IGFBP-2.

We also identified that IGFBP-3 was reduced in SSc without any specific correlation with regards to the severity of lung involvement. Conversely to our observation, many studies have identified that alveolar IGFBP-3 is associated to fibrotic lung process in SSc without any specifications of its circulating levels. Of interest our previous study focusing on IPF patients identified that untreated IPF patients were exhibiting lower serum levels of IGFBP-3 than HS and IPF patients treated with specific anti-fibrotic therapies. We also underlie that patients with ARDS as well as those suffering from cystic fibrosis or COPD presented similar variation of IGFBP-3 than those shown in our study [35].

In our study, serum levels of TGF- $\beta$ were similar for all groups even though TGF- $\beta$ is widely known to be associated with the pathophysiology of fibrosing lung disease [36]. Similarly, our previous study focusing on IPF did not find any difference in TGF- $\beta$ levels between HS and patients suffering from IPF leading to the conclusion that serum TGF- $\beta$ is not a good biomarker of lung fibrosis [15].

YKL-40 was negatively correlated with pulmonary function tests in our study (FEV1, FVC, DLCO) even if there were no significant differences of the serum level between the control group and the SSC group. In the same line, there was no significant difference with regard to the follow-up level at 2 years. Of great interest, the basal level of YKL-40 is still negatively correlated with the FVC at 2-year foolw-up. YKL-40 is a chitinase 3-like protein 1, regulates cell proliferation and survival and is produced by activated macrophages. It acts as a growth factor for connective tissue. Confirmatory to previous studies, we identified that YKL-40 is associated with the lung function impairment of patients suffering from SSc 
[37-39]. Therefore, these observations need further explorations to see whether YKL-40 could act as a predictor of lung degradation for patients with SSc.

IL-8 was also increased in our study in SSc patients. IL-8 is known to be a strong chemotactic agent for neutrophils and can take part to the pathophysiological process of SSc [40] by recruiting neutrophils in lungs [41]. Of interest, it should be noted that blood neutrophils were increased in SSc compared to HS. In the same line, MMP-9 was also increased in SSc context. MMP-9 is known to be actively secreted by neutrophils [42, 43], which are increased in SSc patients.

The impact of maintenance of immunosuppressive drugs on cell count and biomarker levels was not relevant in our study.

\section{Conclusions}

We conclude that IGFBP-2 is increased in patients with SSc in comparison to HS and may play a protective role against the progression of the disease by blocking fibrogenesis process. We certainly need to validate those results in a larger longitudinal trial to confirm the clinical value of these observations.

\section{Abbreviations}

ANA: Antinuclear Antibodies

BRDU: Bromodeoxyuridine

CRP: C-Reactive Protein

DLCO: Diffusion lung capacity for CO

FEV1: Forced expired volume in one second

FVC: Forced vital capacity

IGF-1: Insuline like growth factor-1

IGFBP-1,-2,-3: Insulin like Growth Factor Binding Protein - 1,-2,-3

IL-8: Interleukin-8

ILD: Interstitial lung disease

IPF: Idiopathic pulmonary fibrosis

IQR: Interquartile range

KCO: The carbon monoxide transfer coefficient 
MMP-7,-9: Matrix metalloproteinase -7 and -9

Pro-Col I: Pro-collagen type I

SD: Standard deviation

SSc: Systemic sclerosis

SSc-ILD: Systemic sclerosis associated interstitial lung disease

TGF- $\beta$ : Transforming growth factor $\beta$

TLC: Total lung capacity

TNF-a: Tumor necrosing factor a

YKL-40: Chitinase-3-like protein 1

\section{Declarations}

\section{Ethics approval and consent to participate}

The study protocol was approved by the ethics committee of Hospitalo-Facultaire Universitaire de Liège (CHU Hospital of Liège, Belgian number: B707201422832 ; ref: 2014/302). All subjects gave written consent be for their enrollment.

\section{Consent for publication}

Not applicable.

\section{Availability of data and materials}

The datasets used and analysed during the current study are available from the corresponding author on reasonable request.

\section{Competing interests}

The authors declare that they have no competing interests. MH is employee of Belgian Volition SPRL.

\section{Funding}

There was no funding for this article.

\section{Author contribution}

JG, MSN, RL, MGM designed the study and coordinated the research. JG, FG and MH contributed to collect samples, and carried out the clinical evaluation of patients. MSN, MH, BA, CM and DDS performed 
experiments and analysed the datas. JG and MSN drew figures and wrote the manuscript. All authors reviewed the final version of the manuscript. All authors read and approved the final version of the manuscript. JG, MSN, RL, MGM guaranty the integrity of the work as a whole, from inception to published article.

\section{Acknowledgements}

Thank you to all co-authors for their contribution.

\section{Author information}

Julien Guiot and Makon-Sébastien Njock contributed equally to this work.

\section{Affiliations}

\section{Department of Pneumology, GIGA-I3 Research Group, University and CHU of Liège, Belgium.}

Julien Guiot, Makon-Sébastien Njock, Fanny Gester, Monique Henket, Catherine Moermans, Renaud Louis

\section{Department of Rheumatology, GIGA-I3 Research Group, University and CHU of Liège, Belgium.}

Béatrice André, Dominique de Seny, Michel G. Malaise

\section{Corresponding authors}

Julien Guiot and Makon-Sébastien Njock

\section{References}

1. Katsumoto TR, Whitfield ML, Connolly MK. The Pathogenesis of Systemic Sclerosis. Annu Rev Pathol Mech Dis. 2011;6:509-37.

2. Caron M, Hoa S, Hudson M, Schwartzman K, Steele R. Pulmonary function tests as outcomes for systemic sclerosis interstitial lung disease. Eur Respir Rev. 2018;27:170102.

3. Sánchez-Cano D, Ortego-Centeno N, Callejas JL, Fonollosa Plá V, Ríos-Fernández R, Tolosa-Vilella C, et al. Interstitial lung disease in systemic sclerosis: data from the spanish scleroderma study group. Rheumatol Int. 2018;38:363-74.

4. Schoenfeld SR, Castelino FV. Interstitial lung disease in scleroderma. Rheum Dis Clin North Am. 2015;41:237-48.

5. Solomon JJ, Olson AL, Fischer A, Bull T, Brown KK, Raghu G. Scleroderma lung disease. Eur Respir Rev. 2013;22:6-19.

6. Steele R, Hudson M, Lo E, Baron M, Canadian Scleroderma Research Group. Clinical decision rule to predict the presence of interstitial lung disease in systemic sclerosis. Arthritis Care Res.

2012;64:519-24. 
7. van den Hoogen F, Khanna D, Fransen J, Johnson SR, Baron M, Tyndall A, et al. 2013 classification criteria for systemic sclerosis: an American college of rheumatology/European league against rheumatism collaborative initiative. Ann Rheum Dis. 2013;72:1747-55.

8. Herzog EL, Mathur A, Tager AM, Feghali-Bostwick C, Schneider F, Varga J. Review: Interstitial Lung Disease Associated With Systemic Sclerosis and Idiopathic Pulmonary Fibrosis: How Similar and Distinct? Arthritis Rheumatol. 2014;66:1967-78.

9. Fastrès A, Felice F, Roels E, Moermans C, Corhay J-L, Bureau F, et al. The Lung Microbiome in Idiopathic Pulmonary Fibrosis: A Promising Approach for Targeted Therapies. Int J Mol Sci. 2017;18:2735.

10. Guiot J, Duysinx B, Bonhomme O, Louis R, Corhay J-L. How i treat a patient with idiopathic pulmonary fibrosis. Rev Med Liege. 2017;72.

11. Guiot J, Struman I, Chavez V, Henket M, Herzog M, Scoubeau K, et al. Altered epigenetic features in circulating nucleosomes in idiopathic pulmonary fibrosis. Clin Epigenetics. 2017;9:84.

12. Guiot J, Duysinx B, Seidel L, Henket M, Gester F, Bonhomme O, et al. Clinical experience in idiopathic pulmonary fibrosis: a retrospective study. Acta Clin Belg Int J Clin Lab Med. 2017.

13. Njock M-S, Guiot J, Henket MA, Nivelles O, Thiry M, Dequiedt F, et al. Sputum exosomes: promising biomarkers for idiopathic pulmonary fibrosis. Thorax. 2019;74:309-12.

14. Bonhomme O, André B, Gester F, de Seny D, Moermans C, Struman I, et al. Biomarkers in systemic sclerosis-associated interstitial lung disease: review of the literature. Rheumatology. 2019;61(6 Pt 1):67-9.

15. Guiot J, Moermans C, Henket M, Corhay J-L, Louis R. Blood Biomarkers in Idiopathic Pulmonary Fibrosis. Lung. 2017;195.

16. Guiot J, Struman I, Louis E, Louis R, Malaise M, Njock M-S. Exosomal miRNAs in Lung Diseases: From Biologic Function to Therapeutic Targets. J Clin Med. 2019;8.

17. Inoue Y, Kaner RJ, Guiot J, Maher TM, Tomassetti S, Moiseev S, et al. Diagnostic and Prognostic Biomarkers for Chronic Fibrosing Interstitial Lung Diseases with a Progressive Phenotype. Chest. 2020.

18. Ito Y, Arita M, Kumagai S, Takei R, Noyama M, Tokioka F, et al. Serological and morphological prognostic factors in patients with interstitial pneumonia with autoimmune features. BMC Pulm Med. 2017;17:111.

19. Gester F, Duysinx B, Von Frenckell C, Louis R, Guiot J. [Pattern of biological changes in interstitial lung diseases]. Rev Med Liege. 2019;74:47-53.

20. Raghu G, Collard HR, Egan JJ, Martinez FJ, Behr J, Brown KK, et al. An official ATS/ERS/JRS/ALAT statement: idiopathic pulmonary fibrosis: evidence-based guidelines for diagnosis and management. Am J Respir Crit Care Med. 2011;183:788-824.

21. Godinas L, Corhay J-L, Henket M, Guiot J, Louis R, Moermans C. Increased production of TGF- $\beta 1$ from sputum cells of COPD: Relationship with airway obstruction. Cytokine. 2017;99. 
22. Guiot J, Bondue B, Henket M, Corhay JL, Louis R. Raised serum levels of IGFBP-1 and IGFBP-2 in idiopathic pulmonary fibrosis. BMC Pulm Med. 2016;16.

23. Hirota N, Ito T, Miyazaki S, Ebina M, Homma S. Gene expression profiling of lung myofibroblasts reveals the anti-fibrotic effects of cyclosporine. Tohoku J Exp Med. 2014;233:283-93.

24. Duan C, Xu Q. Roles of insulin-like growth factor (IGF) binding proteins in regulating IGF actions. Gen Comp Endocrinol. 2005;142:44-52.

25. JONES JI CLEMMONSDR. Insulin-Like Growth Factors and Their Binding Proteins: Biological Actions*. Endocr Rev. 1995;16:3-34.

26. Yin $P, X u$ Q, Duan C. Paradoxical actions of endogenous and exogenous insulin-like growth factorbinding protein- 5 revealed by RNA interference analysis. J Biol Chem. 2004;279:32660-6.

27. Brandt K, Grünler J, Brismar K, Wang J. Effects of IGFBP-1 and IGFBP-2 and their fragments on migration and IGF-induced proliferation of human dermal fibroblasts. Growth Horm IGF Res. 2015;25:34-40.

28. Ding H, Wu T. Insulin-Like Growth Factor Binding Proteins in Autoimmune Diseases. Front Endocrinol. 2018;9:499.

29. HAMAGUCHI Y, FUJIMOTO M, MATSUSHITA T, HASEGAWA M, TAKEHARA K. SATO S. Elevated Serum Insulin-like Growth Factor (IGF-1) and IGF Binding Protein-3 Levels in Patients with Systemic Sclerosis: Possible Role in Development of Fibrosis. J Rheumatol. 2008;35:2363-71.

30. Chadelat K, Boule M, Corroyer S, Fauroux B, Delaisi B, Tournier G, et al. Expression of insulin-like growth factors and their binding proteins by bronchoalveolar cells from children with and without interstitial lung disease. Eur Respir J. 1998;11.

31. Guiot J, Henket M, Corhay JL, Moermans C, Louis R. Sputum biomarkers in IPF: Evidence for raised gene expression and protein level of IGFBP-2, IL-8 and MMP-7. PLOS ONE. 2017;12:e0171344.

32. Reeve JG, Morgan J, Schwander J, Bleehen NM. Role for membrane and secreted insulin-like growth factor-binding protein-2 in the regulation of insulin-like growth factor action in lung tumors. Cancer Res. 1993;53:4680-5.

33. Migita T, Narita T, Asaka R, Miyagi E, Nagano H, Nomura K, et al. Role of insulin-like growth factor binding protein 2 in lung adenocarcinoma: IGF-independent antiapoptotic effect via caspase-3. Am J Pathol. 2010;176:1756-66.

34. Brandt K, Grünler J, Brismar K, Wang J. Effects of IGFBP-1 and IGFBP-2 and their fragments on migration and IGF-induced proliferation of human dermal fibroblasts. Growth Horm IGF Res. 2015;25:34-40.

35. Ahasic AM, Zhai R, Su L, Zhao Y, Aronis KN, Thompson BT, et al. IGF1 and IGFBP3 in acute respiratory distress syndrome. Eur J Endocrinol. 2012;166:121-9.

36. Khalil N, Greenberg AH. The role of TGF-beta in pulmonary fibrosis. Ciba Found Symp. 1991;157:194-207; discussion $207-11$. 
37. Cossu M, van Bon L, Preti C, Rossato M, Beretta L, Radstake TRDJ. Earliest Phase of Systemic Sclerosis Typified by Increased Levels of Inflammatory Proteins in the Serum. Arthritis Rheumatol. 2017;69:2359-69.

38. La Montagna G, D’Angelo S, Valentini G. Cross-sectional evaluation of YKL-40 serum concentrations in patients with systemic sclerosis. Relationship with clinical and serological aspects of disease. J Rheumatol. 2003;30:2147-51.

39. Nordenbæk C, Johansen JS, Halberg P, Wiik A, Garbarsch C, Ullman S, et al. High serum levels of YKL-40 in patients with systemic sclerosis are associated with pulmonary involvement. Scand $J$ Rheumatol. 2005;34:293-7.

40. Schnyder B, Bogdan JA, Schnyder-Candrian S. Role of interleukin-8 phosphorylated kinases in stimulating neutrophil migration through fibrin gels. Lab Investig J Tech Methods Pathol. 1999;79:1403-13.

41. Kadono T, Kikuchi K, Ihn H, Takehara K, Tamaki K. Increased production of interleukin 6 and interleukin 8 in scleroderma fibroblasts. J Rheumatol. 1998;25:296-301.

42. Kim W-U, Min S-Y, Cho M-L, Hong K-H, Shin Y-J, Park S-H, et al. Elevated matrix metalloproteinase-9 in patients with systemic sclerosis. Arthritis Res Ther. 2005;7:R71.

43. Distler O, Highland KB, Gahlemann M, Azuma A, Fischer A, Mayes MD, et al. Nintedanib for Systemic Sclerosis-Associated Interstitial Lung Disease. N Engl J Med. 2019;380:2518-28.

\section{Figures}

\section{SSc patients $(n=102)$ vs Healthy Subjects $(n=39)$}

- Pulmonary function tests

- Quantification of serum biomarkers

- Correlation analysis

(Pulmonary function tests/Serum biomarker concentrations

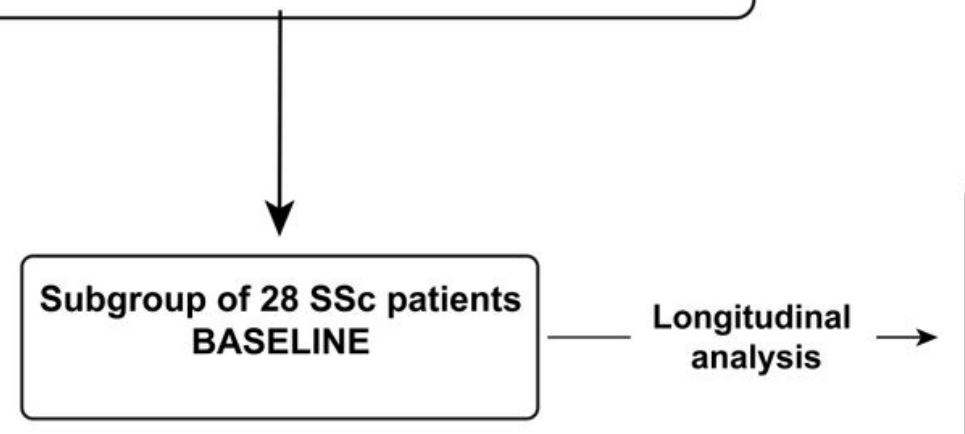

\section{Subgroup of 28 SSc patients} 2-YEAR FOLLOW-UP

- Pulmonary function tests

- Quantification of serum biomarkers

- Correlation analysis

(Pulmonary function tests/ $\Delta$ Serum biomarker concentrations)

\section{Figure 1}

Schematic illustration of the study design 

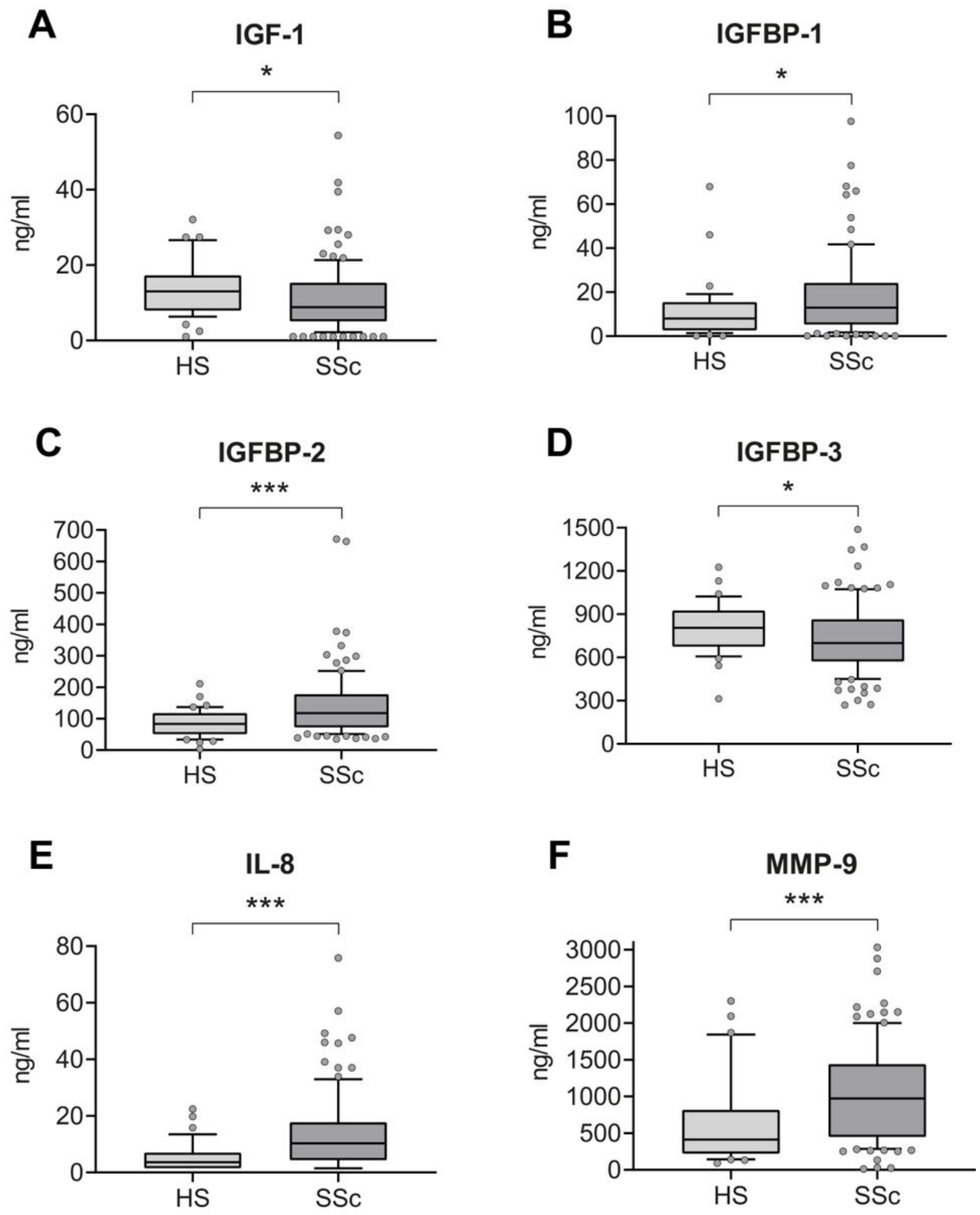

\section{Figure 2}

Serum biomarkers in SSc patients compared to HS. Comparison of the concentration of (a) IGF-1, (b) IGFBP-1, (c) IGFBP-2, (d) IGFBP-3, (e) IL-8 and (f) MMP-9 in SSc patients and HS. Data are expressed as median (IQR $-\mathrm{Cl} 90 \%$ ). ${ }^{*} p<0.05 * \star p<0.01 * \star * p<0.001$ compared to HS. Abbreviations: HS = healthy subjects; IGF-1 = Insuline like growth factor-1; IGFBP-1 , -2, -3 = Insulin like Growth Factor Binding Protein $-1,-2,-3 ;$ IL-8 = Interleukin-8; MMP-9 = Matrix metalloproteinase-9; SSc = Systemic sclerosis. 


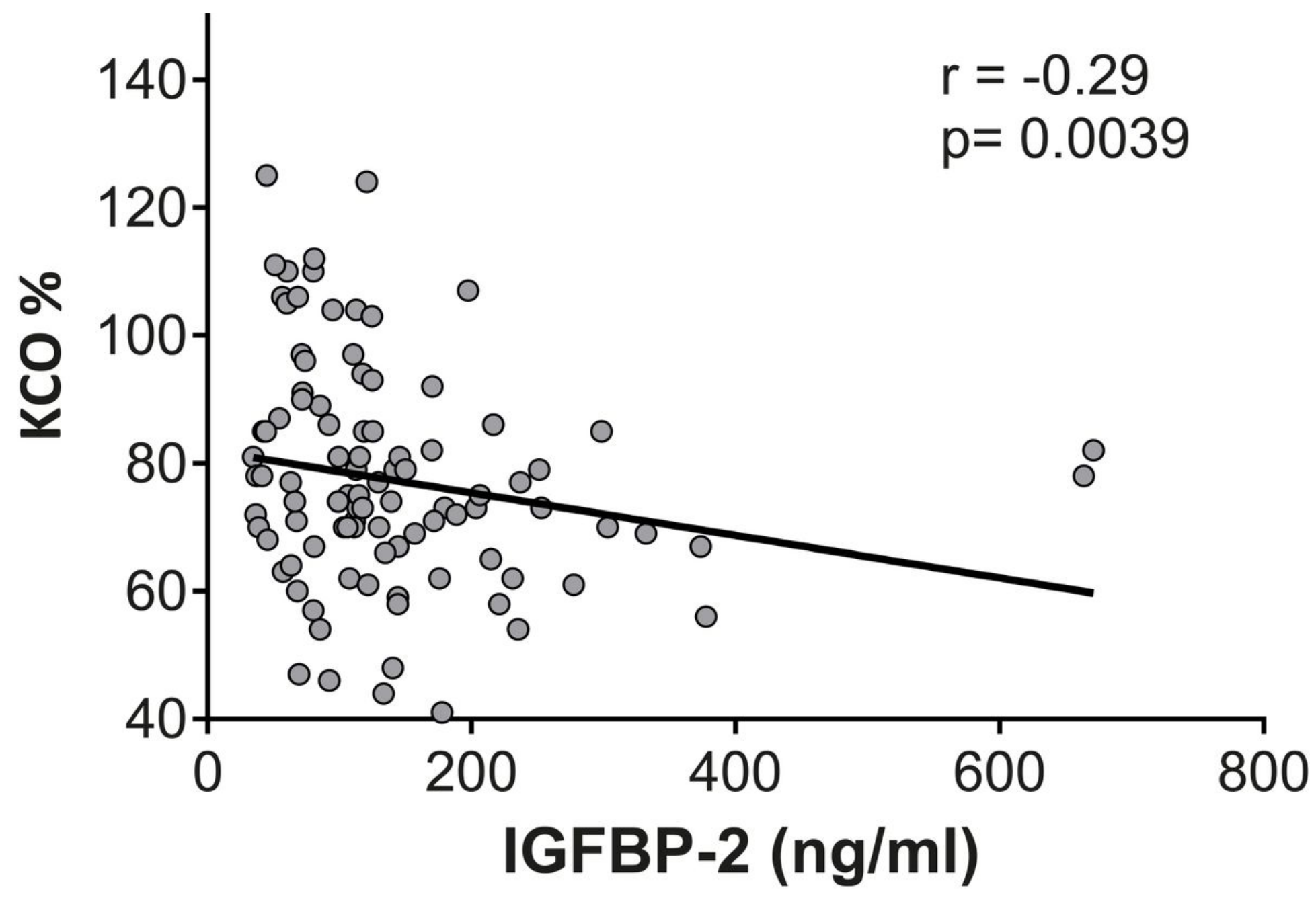

Figure 3

Correlation at baseline between $\mathrm{KCO}$ (\% pred) and IGFBP-2 levels in SSc cohort. Abbreviations: IGFBP-2 = Insuline-like growth factor-2; KCO = The carbon monoxide transfer coefficient. 
A

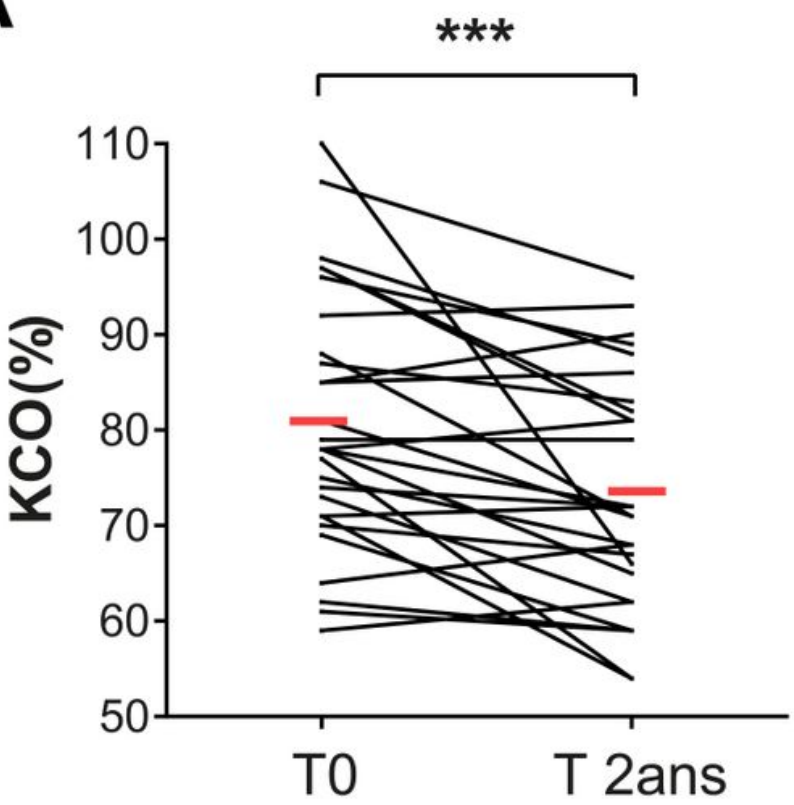

B

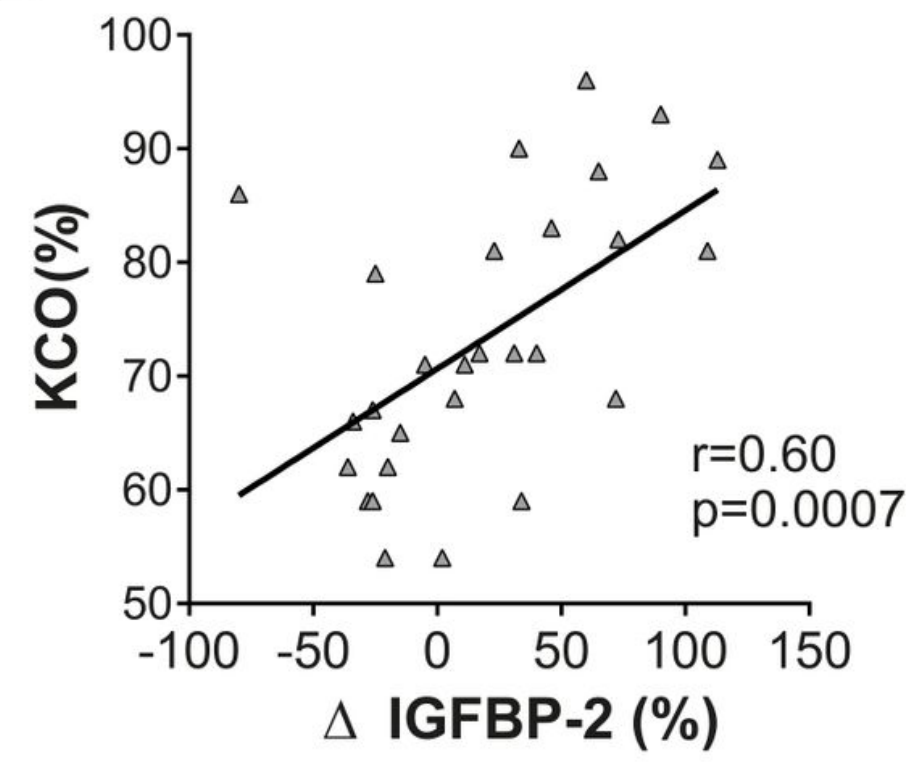

C

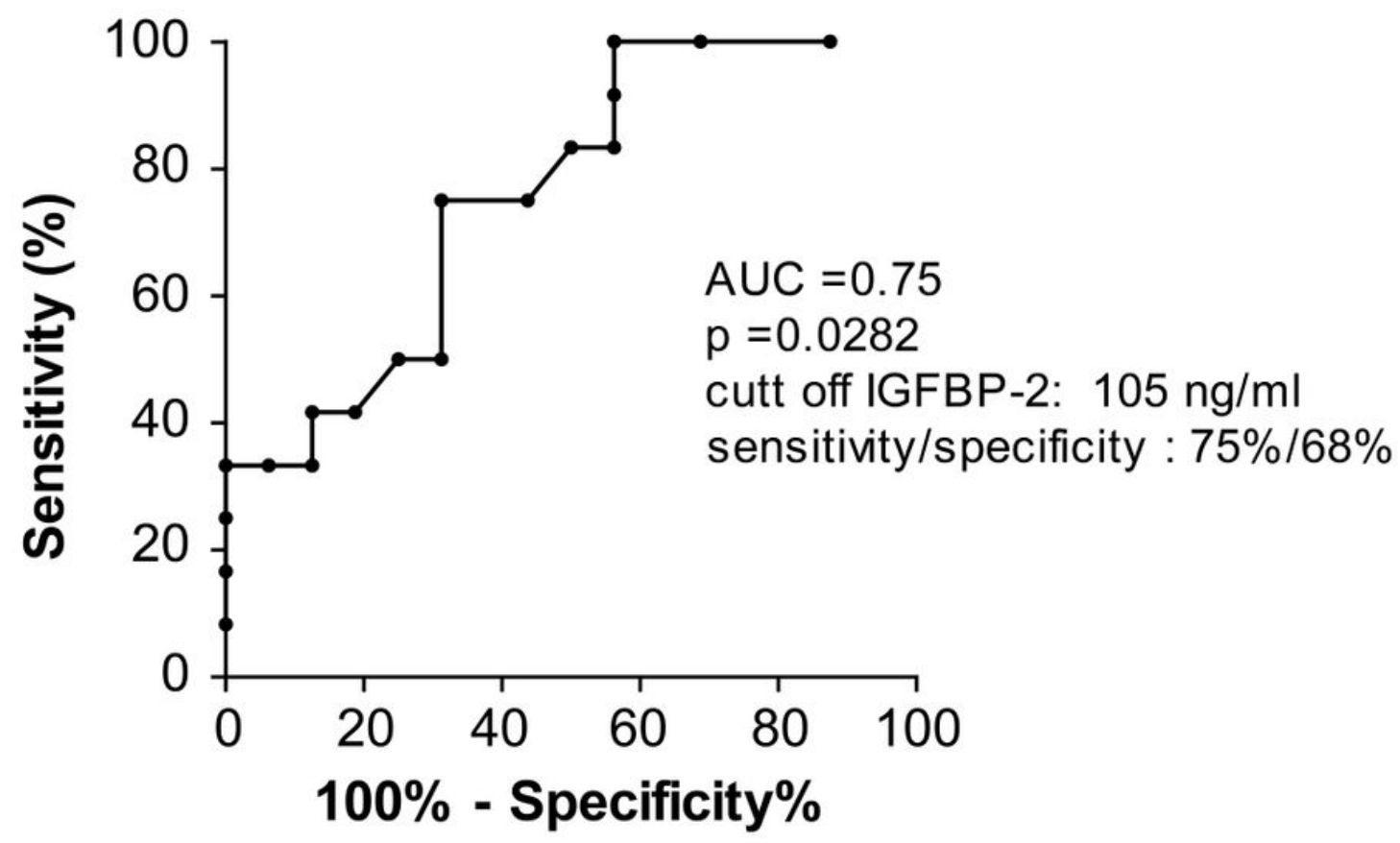

Figure 4

Longitudinal analysis. (a) KCO variation in the 2-year longitudinal analysis. $* \star \star x<0.001$. (b) Correlation study between KCO at 2-yars and IGFBP-2 variation between baseline and 2-year follow-up. (c) ROC curve analysis showing that baseline levels of IGFBP- $2<105 \mathrm{ng} / \mathrm{ml}$ predict preserved $\mathrm{KCO}(>70 \%$ pred) at 2 years. Abbreviations: AUC = area under the curve; IGFBP-2 = Insuline-like growth factor-2; KCO = The carbon monoxide transfer coefficient. 
A

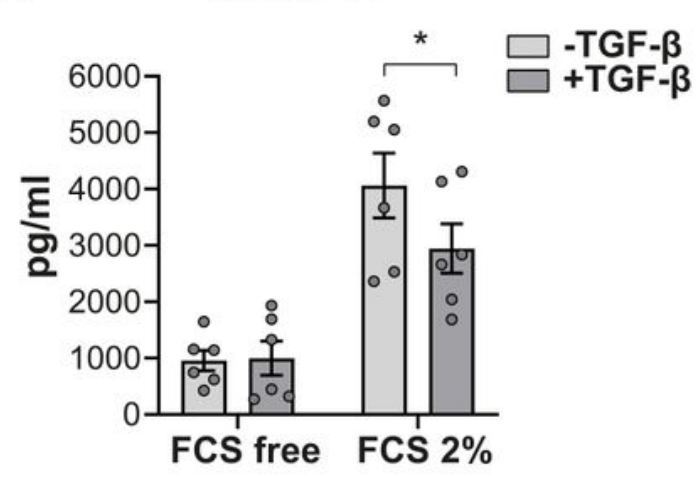

B

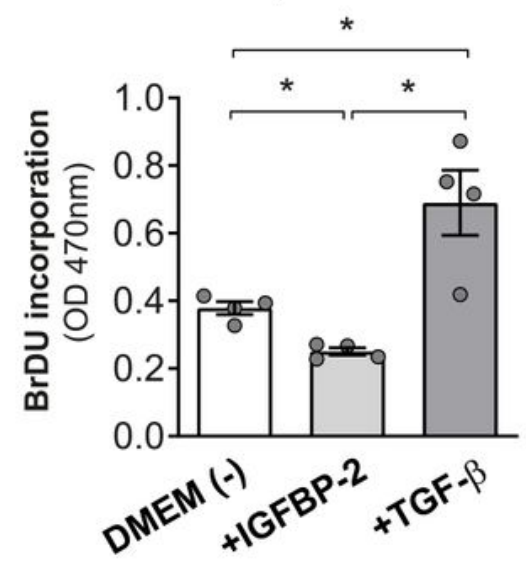

D

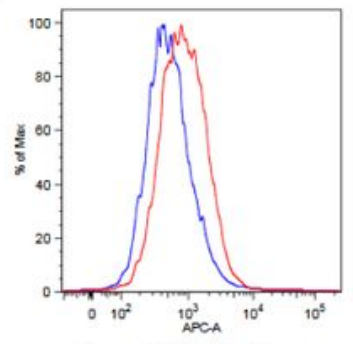

1. IGFBP-2

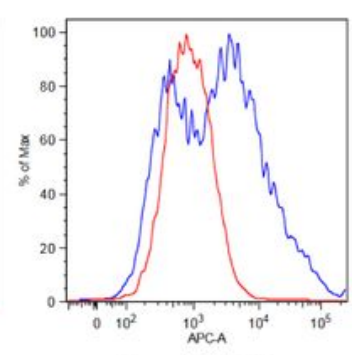

2. TGF- $\beta$

\begin{tabular}{|c|c|c|c|}
\hline $\begin{array}{c}\text { Mean } \\
\text { Fluorescence }\end{array}$ & DMEM & $\begin{array}{c}\text { IGFBP-2 } \\
(\mathbf{1 0 0 n g / m l})\end{array}$ & $\begin{array}{c}\text { TGF- } \boldsymbol{\beta} \\
(\mathbf{5 n g} / \mathbf{m l})\end{array}$ \\
\hline T48h & 2020 & 1743 & 11949 \\
\hline $\begin{array}{c}\text { \%labeled } \\
\text { cells }\end{array}$ & 42.4 & 25.2 & 65.2 \\
\hline
\end{tabular}

C

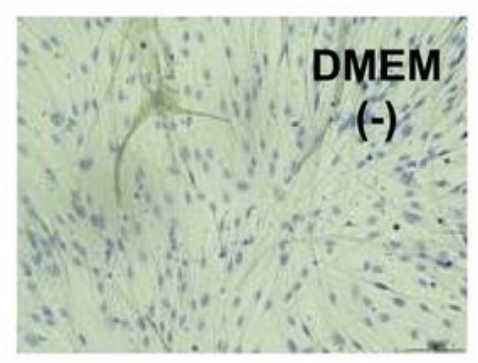

IGFBP-2
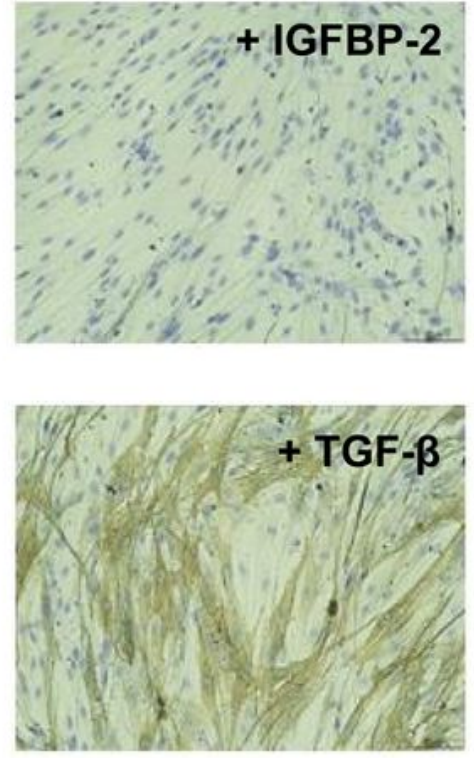

E

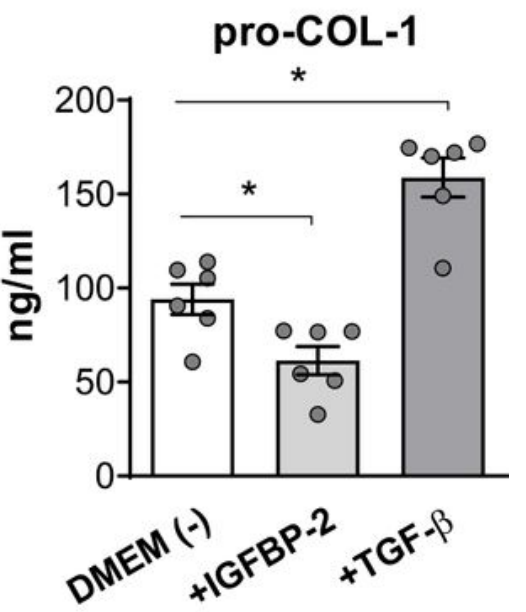

Figure 5

Evaluation of IGFBP-2 properties on human lung fibroblasts. (a) Secretion of IGFBP-2 by HLF fibroblasts at basal state (FCS free) and in pro-proliferative condition (FCS, $2 \%$ ) without or with TGF- $\beta(n=6)$. (b) Effect of IGFBP-2 on HLF proliferation assessed by BrdU assay. (c-d) Effect of IGFBP-2 on fibrotic activity of HLF fibroblasts assessed by measuring a-SMA by (c) immunocytochemistry (a-SMA, brown) and (d) FACS analysis. FACS analysis of a-SMA comparing HLF fibroblasts under DMEM condition (red) and 
studied medium (blue) (in presence of IGFBP-2 or TGF- $\beta$ ) $(n=2)$. (e) Effect of IGFBP-2 on the secretion of pro-collagen I of HLF fibroblasts. ${ }^{\star} p<0.05,{ }^{\star *} p<0.001,{ }^{\star \star \star} p<0.0001$. Abbreviations: $\mathrm{BrdU}=$ Bromodeoxyuridine; DMEM = Dulbecco's Modified Eagle Medium; FCS = Fetal Calf Serum; IGFBP-2 = Insuline-like growth factor-2; Pro-Col I = Pro-collagen type I; TGF- $\beta=$ Transforming growth factor $\beta$.

\section{Supplementary Files}

This is a list of supplementary files associated with this preprint. Click to download.

- Additionalfile1Guiotetal.pdf

- Additionalfile2Guiotetal.pdf 